\title{
Design on Security Alarming System of Vehicle terminal equipment
}

\author{
Tong-Liang FAN ${ }^{1, a}$, Wen $\mathrm{Ye}^{1}$ \\ ${ }^{1}$ Department of Electronic Technology, China Maritime Police Academy, Ningbo 315801, China \\ ${ }^{a}$ Corresponding author:libufan432@163.com
}

\begin{abstract}
With the application and extension of the technology of networked vehicles, its security has already become a research focus in recent years. However, the security risk of the vehicle terminal is rarely considered. In this paper, we designed a security alarming system of vehicle terminal equipment. In this system, a variety of sensors are chosen to collect information. The network transmission module TC35i is used to sent a short message to the owner, so as to achieve the monitoring of vehicle security. This system is not only simple in structure, but also easy to adjust and use.
\end{abstract}

\section{Introduction}

With the popularity of vehicles and the development of mobile ad hoc network, The Vehicular Ad Hoc Networks which is regarded as one important realization approach of internet of vehicles has attracted great development. A vehicle in VANET is mainly considered as a node to form an inter-vehicle communication network. Usually, dynamic vehicular mobile communication systems include inner-vehicle communication systems, such as Vehicle to Sensor, and communication with other entities, such Vehicle to Infrastructure, Vehicle to Human and Vehicle to Internet [1-3]. Recently, The IoV will play an important role in the clean traffic environment, with increasing number of system technologies and system intelligence designs. What's more, security has already become a research focus in recent years [4]. The primary goal for the internet of vehicles is to ensure that the sensor node for collecting traffic information can provide perceives data accurately, and timely. In order to guarantee the authenticity and reliability of the result in data fusion $[5,6]$, which described the involved technologies of vehicle Internet information terminal such as on-board diagnosis (OBD), GPRS communication, GPS positioning and speech synthesis.

The development and application of vehicular network is an important technical means of intelligent transportation system. The existing active safety equipment is developed independently by manufactures. However, the vehicle terminal security issues are often neglected. For example, the children was left in the can, and lead to death. In aspect of vehicle safety, we have desired a safety hazard reminder of vehicle terminal based on STC12 microcontroller, and TC35i as the network transmission module, OBD- II as the vehicle state monitoring module. In addition, it adopts multiple sensors to monitor the security of vehicles, and the RFID module to realize intelligent interaction, which achieves the remote constant supervision inside the vehicles. The result of the system test has mainly met the command of the design and gives alarms to the hazard.

\section{System Composition and Function}

\subsection{System structure}

The system mainly consists the acquistion terminal and control terminal. The system structure is illustrated in figure1. The system adoption mold piece turns a design, each function designs into an independent mold piece.

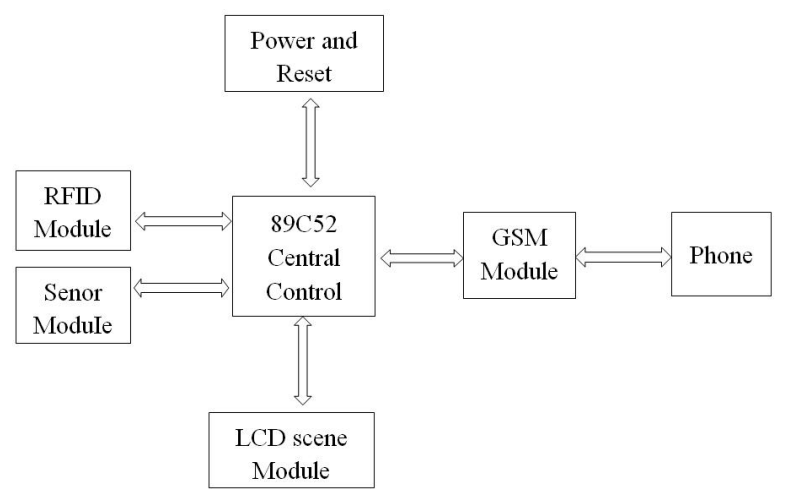

Figure 1. System Architecture

The circuit of system is shown figure 2. The hardware design of nodes needs to ensure the 
following aspects: low consumption of power, good performance of the radio frequency, miniaturization, low cost, compatibility, etc. The main control module uses 89 C52 single chip, which control the operation of system. The wireless communication module use TC35i, which sent a short message to the owner. The module of OBD- II is used to examination the vehicle driving situation. The HC-SR501 is an auto control module based on infrared technology. Temperature/humidity sensor takes DHT11 digital temperature/humidity sensor, whose digital signal output has been calibrated. The product is of high reliability and excellent long-term stability. Gas leakage alarm MQ-2 is highly sensitive to liquid gas, propane and hydrogen. The RFID module is used to find vehicles.

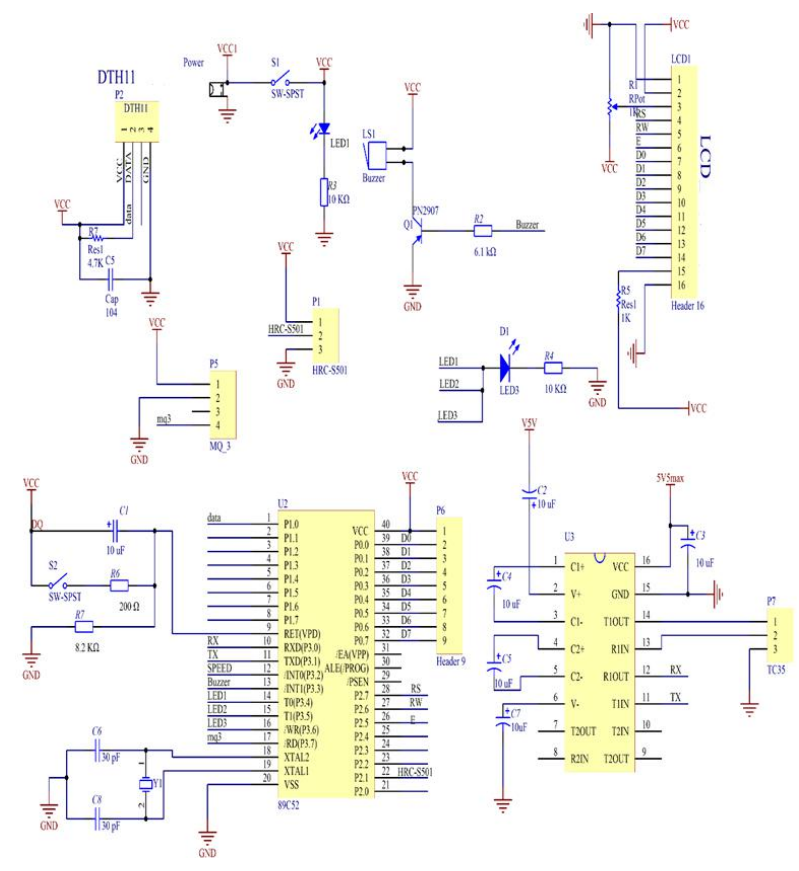

Figure 2. The Circuit of System Hardware

\subsection{The system function}

The main function is automatically vehicle safety alarm. Use OBD- II the condition of mold piece monitor vehicle, and analyze it to circulate present condition and safe circumstance inside the car. When the vehicle is placed in to launch status, the system use alcohol sensor and combustible air sensor to collect a dangerous air information, when explore dangerous air send out an alert and send out a message to the cellular phone, remind that the driver drives after drinking. Judge if there are other combustible gas or not, for example the perfume vaporizes gas, prevent from the occurrence of a fire. When the vehicle motor closes for more than five minutes, moving temperature and humidity sensor and infrared sensor collect an information, whether the examination environment inside the car is comfortable, in order to prevent occurrence someone suffocated while going to bed in the car. Judge inside the car if someone for example leaves behind a child, and sends out a different hint information according to the enactment condition. This system can also sent out a message to open an air condition or seeks the car function like this in the so big parking lot. Mainly make use of a RFID module, when the car owner walks to vehicle side, briefing on device can respond a car owner according to the ID information and automatically open a car door.

\section{The System Hardware Design}

The whole systemis composed of the following.

\subsection{Control module}

The micro controller $89 \mathrm{c} 52$ as the central device and "heart" of the whole system, receives the alarm signal, controls and coordinates the proper functioning of functional modules. The machine is more opposite than general of 8051 micro controller. It has two ports which can be better realization mostly function generally, and its capacity of resisting disturbance also particularly is strong. So it can shield the external disturbance. Don't need an appropriative editor, programming in application directly is a superiority .Programming can better match is at the control of electrical engineering.

\subsection{Wirelss transmission module}

TC35i has an achievement in three things. Firstly, it consumes low and the physical volume of it is small. Secondly the weight is light. It is responsible for message and GPRS data to hand over with each other. The integration level of it is highly. Taking radio frequency electric circuit and radicle the system connecting together. Siemens Company also provided an AT order for customer to program easily. It adopts PDU mode and TXET mode in receiving and dispatching message, so it is easy to operation instruction better.

\subsection{LCD module}

Display module adopts LCD-1602 to show pictures. It has already saved 160 different character list sketch. In this design, display module which be used for displaying the environment in the car. When sensing the owner of the car, showing a number ID for the RFID module identifying in the screen.

\subsection{RFID module}

The RFID module is divided into two basic parts. One is interrogator, and the other is electronics label. The module has two kinds of work methods. There are read-only and write-only. Because of in this system, we only need to identify the owner of cars, choosing the style of read-only. The blast-off frequency of RFID 
mold piece is $13.56 \mathrm{MHz}$ at the same time. Theoretically maximum transmission is 40 meters.

\subsection{Acuistition module}

The alcohol senor MQ-2 spreads a feeling machine to have very high and intelligent degree to distinguish alcohol, and the effective signal is low electricity, so it can be used for this design directly.

HC-SR501 is according to infrared ray technical of auto control module. It adopts German original package importing the LHI778 stretch forward a design, intelligent degree highly and the credibility is strong. It works on the super low electric. It adopts a full-automatic work method for responding.

DHT11 is composite sensor to monitor temperature and humidity of the car. It has small physical volume, the lowest achievement consumes, and 4 needle list the row lead a feet to pack for welding easily.

\section{Software Design}

The main procedure use $\mathrm{C}$ language of system writes, and compiled by Keil $\mathrm{C}$ is guided to the microcomputer. The adoption modularization of programming, after compiling the program for each module, combine some functions to carry out the function of each mold piece, be finally carry on overall debugging .Software flow chart such as Fig.3 show, among them network module the function is more complicated, and is the whole system to carry on the center that the information exchanges, and emphasize stress to carry on program to the network function.

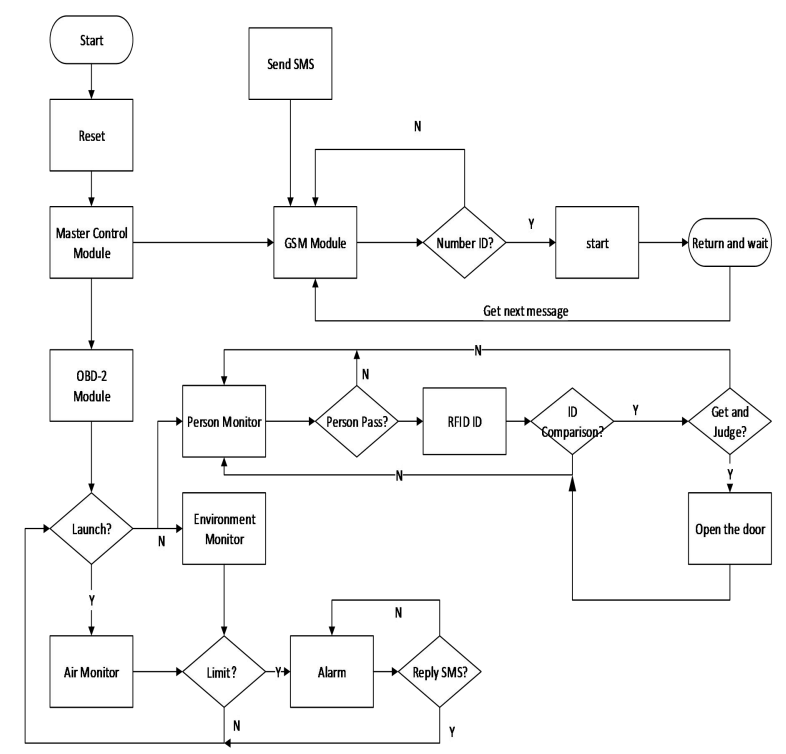

Figure 3. The Flow Chart of System

The system first to examination of OBD-II module, look into whether vehicle's professional drives status, if not vehicle's professional drive status, and then open the temperature and humidity sensor module and infrared sensor module carries on a monitor to the environment inside the car, the monitor is the time of someone in the car, environment whether under the normal status. If the professional drives status and then carries on a monitor to the air, monitor whether drive after drinking and inside the car whether have combustible air, once reaching the threshold carry on reporting to the police. At the same time, when the car is not in the state of travel, the RFID module also automatically opens, be someone pass by of time, judge if it is a car owner. Sending out a message for GSM module under all circumstances, the GSM module delivers the information to the center processing module, pass an order, open a car window with the electrical engineering, turn on lamp or open the air condition in the car, carry out the function of auto control.

\section{System Testing and Analysis}

Next, we put the design through a preliminary test such as the figure 4 . Testing process is divided into two parts. One is single module testing, the other one is the whole design testing.

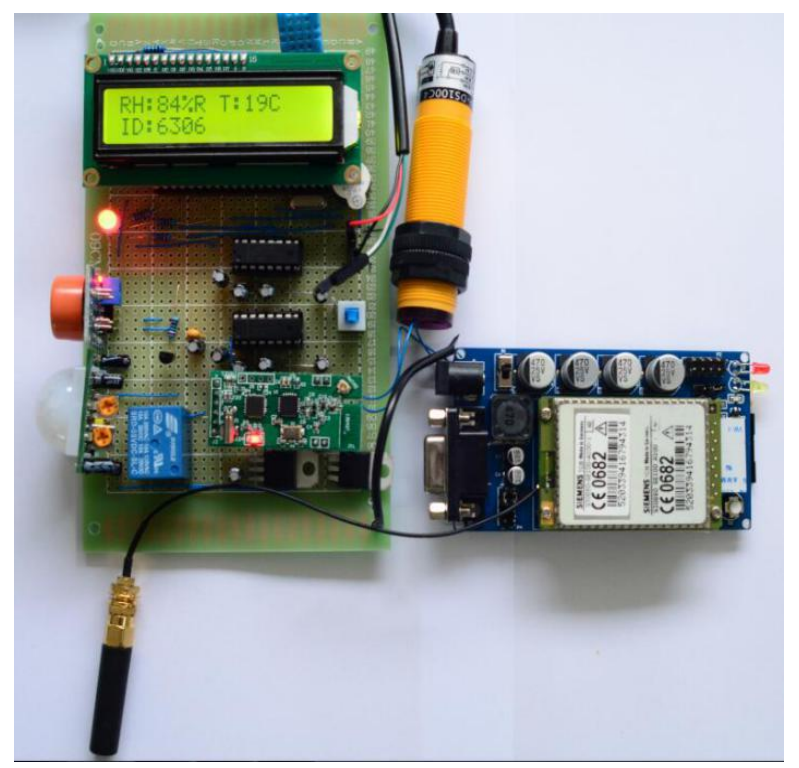

Figure 4. The Design Of Connected Vehicles Hazard Prompter

\subsection{Temperature and humidity sensor module test}

Firstly, we tested the module of temperature and humidity. At different times of the day, we get temperature and humidity test in different periods in the car, because the module is more sensitive to temperature and humidity. The result of test such as table 1 shows.

Table 1. Table of Temperature Result

\begin{tabular}{|c|c|c|c|c|c|}
\hline Time & $\begin{array}{c}7: \\
00\end{array}$ & $\begin{array}{c}11: 0 \\
0\end{array}$ & $\begin{array}{c}15: \\
00\end{array}$ & $19: 00$ & $\begin{array}{c}23: 0 \\
0\end{array}$ \\
\hline Temperature & $\begin{array}{c}12 \\
{ }^{\circ} \mathrm{C}\end{array}$ & $23^{\circ} \mathrm{C}$ & $19{ }^{\circ} \mathrm{C}$ & $16^{\circ} \mathrm{C}$ & $11{ }^{\circ} \mathrm{C}$ \\
\hline humidity & 79 & 72 & $71 \%$ & $76 \%$ & $73 \%$ \\
\hline
\end{tabular}




\begin{tabular}{|l|l|l|l|l|l|}
\hline & $\%$ & $\%$ & & & \\
\hline
\end{tabular}

The test environment is placed in the end of November deep autumn of rather wave. It can reflect whether the car environment is comfortable.

\subsection{Automatic door control}

Secondly, we tested the module of Automatic door control. Under the different scene, imitating whether the car door will open. At test of time, pass light putting on or putting out to mean the door open or close. The result of test such as table 2 shows.

Table 2 Experimental Door Control Result Table

\begin{tabular}{|c|c|c|c|}
\hline Number & People Pass & Distance( meter) & light \\
\hline 1 & Yes & 53 & NO \\
\hline 2 & Yes & 30 & Yes \\
\hline 3 & Yes & $21($ Wall) & NO \\
\hline 4 & No & 5 & NO \\
\hline 5 & NO(object) & 2 & YES \\
\hline
\end{tabular}

From test the result we can know, RFID module responded to once be apart from too far and not too match an actual circumstance and needed to be improved for adjusting the induction distance of module. Making its control is in the suitable distance inside. And the car door open after 5 automatic close, matching an actual application circumstance. Next, we will improve to the design.

\subsection{Alcohol test}

Thirdly, we tested the function of the alcohol senor MQ-3. Carrying on experimenting inside the car. And the design responded with the buzzer whether existence alcohol. When discovering in the car to have the circumstance of alcohol wet, the buzzer alarm.

Next, we tested the infrared sensors in the car inner part. When the light is green showing responding the person. At the same time, the light become red showing responding no person. The result of test such as table 3 shows.

Table 3 Experimental Human Result Table

\begin{tabular}{|c|c|c|}
\hline Number & body length & color \\
\hline 1 & $170 \mathrm{~cm}$ & Green \\
\hline 2 & No person & Red \\
\hline 3 & $60 \mathrm{~cm}$ & Green \\
\hline 4 & No person inside & Red \\
\hline
\end{tabular}

\subsection{Vehicle identification}

The final commissioning is the open air conditioning function and yard function automatically find the car, to open air conditioning simulation scene, test, motor is used to replace the air conditioning in the operation, the actual process is will the reminder and the car connected to a computer. When the mobile phone sends the message: 'kongtiao (Air conditioner)', the simulation of the motor automatically rotates the air conditioner. According to the program, send the command "T21", when the indoor temperature reached 21 degrees, automatically stop the operation of the air. Mobile phone to send message 'xunche (Search cars)', the prompt device on the color light flashes always change color cue position.

\section{Conclusion}

Vehicular network is one of the important research directions in intelligent transportation field. A Security Alarming System for vehicular network was developed. The design takes $89 \mathrm{C} 52$ as the core module of data acquisition terminal. It can give an alarm by mounting temperature humidity sensor, gas sensor and the infrared induction device.This system has strong practical value and broad market development prospects with features of simple structure, strong stability and low cost. It can be easily used in the practical applications.

\section{References}

1. Wan, J.; Zou, C.; Zhou, K.; Lu, R.; Li, D. IoT Sensing Framework with Inter-cloud Computing Capability in Vehicular Networking. Electron. Commer. Res. 2014, 14, 389-416. [CrossRef]

2. Liu, N. Internet of Vehicles: Your Next Connection. Available online: http://www.huawei.com/es/static/ HW-110848.pdf (accessed on 20 December 2015).

3. Chen, M.; Mau, D.; Zhang, Y.; Taleb, T.; Leung, V. VENDNET: Vehicular Named Data Network. Veh. Commun. 2014, 1, 208-213. [CrossRef]

4. Wu Chuankun.A Preliminary Investigation on the Security Architecture of the Internet of things[J].Bulletin of ChineseAcademy of Sciences, 2010(4):411-419.

5. Huang C-L, Fallah YP, Sengupta R, Krishnan H. Adaptive intervehicle communication control for cooperative safety systems[J]. Network, 2010, 24(1): 6-13.

6. R Anbazhagan, S Vanangamudi, C Thamotharan. Design of Intelligent Car Security System. Middle East Journal of Scientific Research, 2014, 20(10):1229-1233. 